\title{
A battery-less power supply using supercapacitor as energy storage powered by solar
}

\author{
Mohammad Hadin A. Malek, Farahiyah Mustafa, Anis Maisarah Mohd Asry \\ Faculty of Engineering Technology, Universiti Tun Hussein Onn Malaysia, Malaysia
}

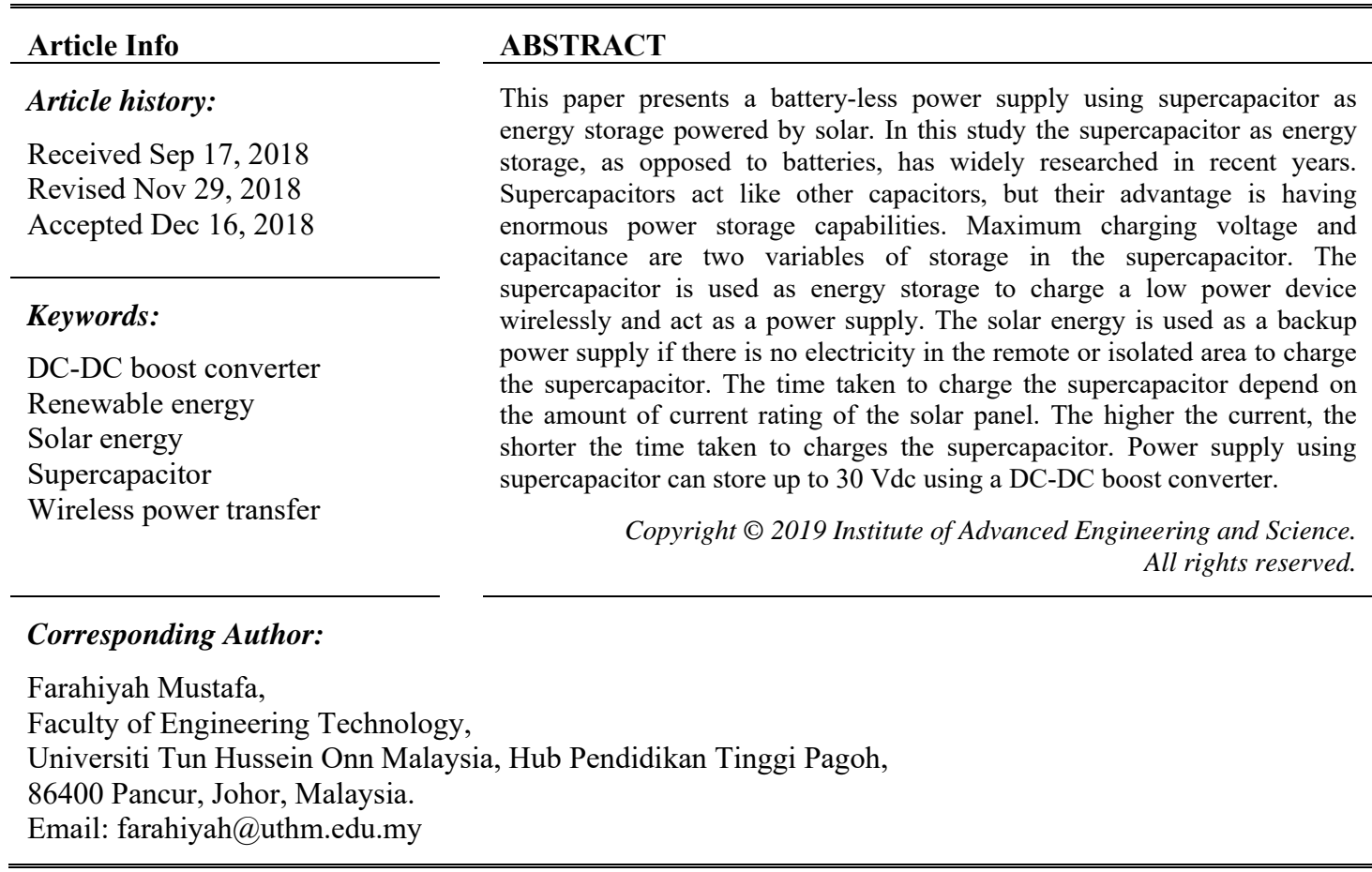

\section{INTRODUCTION}

Powerbank is simply an external energy storage that is used to store charges that could carry a high capacity of power. Normally, batteries are used as an energy storage system (ESS) because it has high energy density and low maintenance. Another option of ESS is by applying supercapacitor. This is because supercapacitor has gigantic power storage capabilities.

There have been numerous approaches for the supercapacitor since it has fast charging and discharging cycle [1], [2]. There are some research done by applying supercapacitor as energy storage such as modelling of battery-supercapacitor hybrid energy storage system [3]. The researcher combined the supercapacitor with the battery to connect in the system to determine the efficiency of the supercapacitor as energy storage. In the supercapacitor, energy is stored electrostatically on the surface of the material and does not involve chemical reactions [4]. The supercapacitor can be charged quickly, leading to a very high power density, and do not lose their storage capabilities over time [4]. In this study, the supercapacitor is chosen as energy storage for dual functional wireless and power supply unit.

Wireless power transfer (WPT), in which electric power is transmitted through the overlapping magnetic fields of a transmitter and receiver, is used as features of this study to charge a lower device wirelessly. WPT is a promising technology based on electromagnetic theory and radiowave theory, representing the combined application of electrical and radio science [5]. In previous research that applying WPT concept such as electric vehicle charging [6], [7], power transmission system [8], wireless charger for mobile phone [9] shows that the important part of the WPT is the transmitter and the receiver. The function of the transmitter coil is to transfer the current by using magnetic flux to the receiver coil. Low power 
efficiency and limited transfer range are the two main issues of WPT. Higher efficiencies are only achieved at very short transmission distances between transmitter and receiver [10].

Solar panel has been studied to be used as a backup power supply to charge the supercapacitor. The previous study is using solar power for power up a boat [11], [12]. In this study the sunlight is used to power up a boat and it represent the most successful and attractive application of PV in the field of sustainable transport.

This paper presents a battery-less power supply using supercapacitor as energy storage powered by solar. In this study the development of a battery-less power supply using supercapacitor as energy storage powered by solar has been studied. The solar panel is used in this study to charge the supercapacitor. In order to boost up the voltage of the supercapacitor before it charge the device, the DC-DC boost converter is used. The DC-DC boost converter in this study is used the XL6007 as a main part of that circuit. Then the output from the module can be used to power up many other electronic device such as mobile phone, speaker, flashlight and etc.

\section{RESEARCH METHOD}

Figure 1 shows the flow chart of this research. This flowchart shows how the whole system dual functional of wireless and power supply using supercapacitor as energy storage.

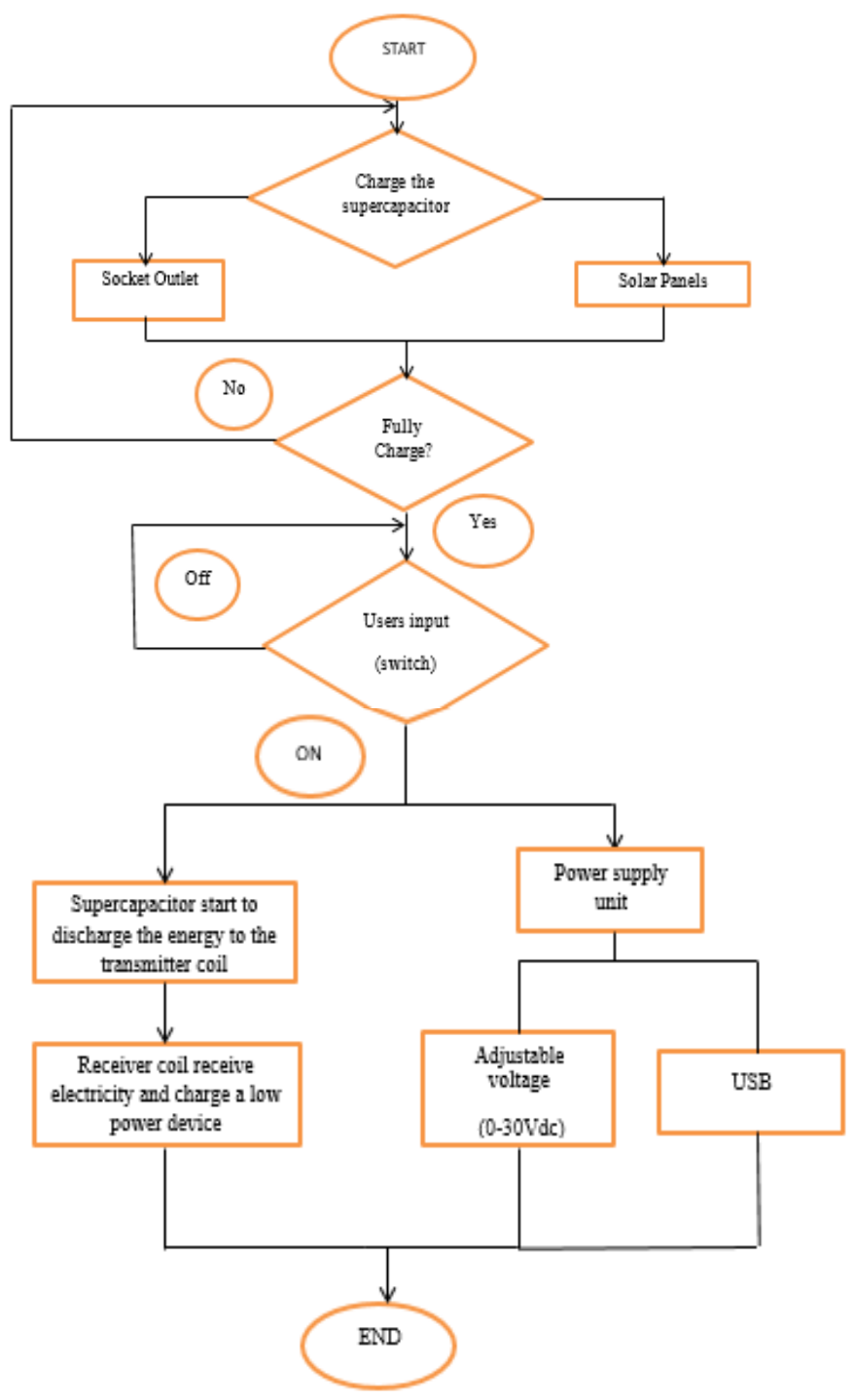

Figure 1. Flow chart of the whole project 
Power source is needed to power up every devices and technologies to make that system work well. In this study, solar panel or socket outlet is used as a power source in order to charge the supercapacitor.Then the charge from this supercapacitor is used to power up low power devices. The function of the supercapacitor in this study is it acts as batteries to store the energy. Next, supercapacitor will discharge the energy stored and goes to the transmitter coil to transmit the electricity. The function of the transmitter coil is to transfers the current by using magnetic flux to the receiver coil and then will charge a low power device. Besides that, supercapacitor also can be used as a power supply (maximum $30 \mathrm{Vdc}$ ) by using dc-dc boost converter. Boost converter with USB type male connecter also used to produce the fixed 5V output voltage to operate low power devices such as a speaker, flashlight, dc motor or etc.

In order to step up the voltage of the supercapacitor, DC-DC Boost Converter is used. In this study, the boost converter could step up the voltage up to $25 \mathrm{Vdc}$ and can be used as a power supply unit. This study used module of dc-dc boost converter using XL6009 as main chip. Figure 2 shows the schematics diagram ofXL6009 DC-DC Boost Converter.

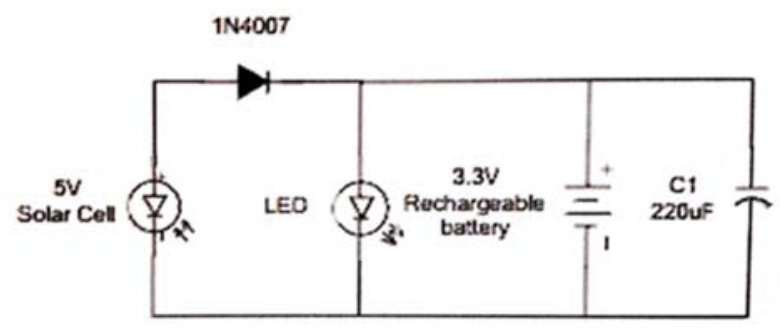

Figure 2. Schematic diagram of XL6009 DC-DC boost converter

In this circuit, the XL6009 is used as a main part. The current from the input voltage flow to the inductor then go through the pin 3 (SW) of the XL6007. During switching with high speed of frequency, the energy stored is released. The discharge of this energy has a greater voltage and being rectified by Schottky diode, SS34. This output voltage go through the voltage divider potentiometer R1 and R2 then go to pin 5 . Then, it goes into the amplifier circuit. After that it goes to the comparator and into the RS Flip-Flop circuit to control the switching frequency. The high frequency still exists on the diode, although it has been rectified. This frequency still leak. In order to avoid this from happening, the capacitor $200 \mu \mathrm{F}$ is used as a filter.

\section{RESULTS AND ANALYSIS}

Figure 3 shows the circuit diagram of the supercapacitor. Two pieces of $500 \mathrm{~F}$ supercapacitors with voltage rating of $2.7 \mathrm{~V}$ are connected in series to double up the voltage to the maximum voltage that can be charged is $5.4 \mathrm{~V}$ but the capacitance will become half. While 5 pieces of $4 \mathrm{~F}$ and 8 pieces of $2 \mathrm{~F}$ is connected in parallel because the voltage rating is already $5.5 \mathrm{~V}$. The supercapacitor is attach together in parallel connection to increase the capacitance value so it could store more energy and could act as a battery. Figure 2 shows that the total capacitance is 541 Farads.

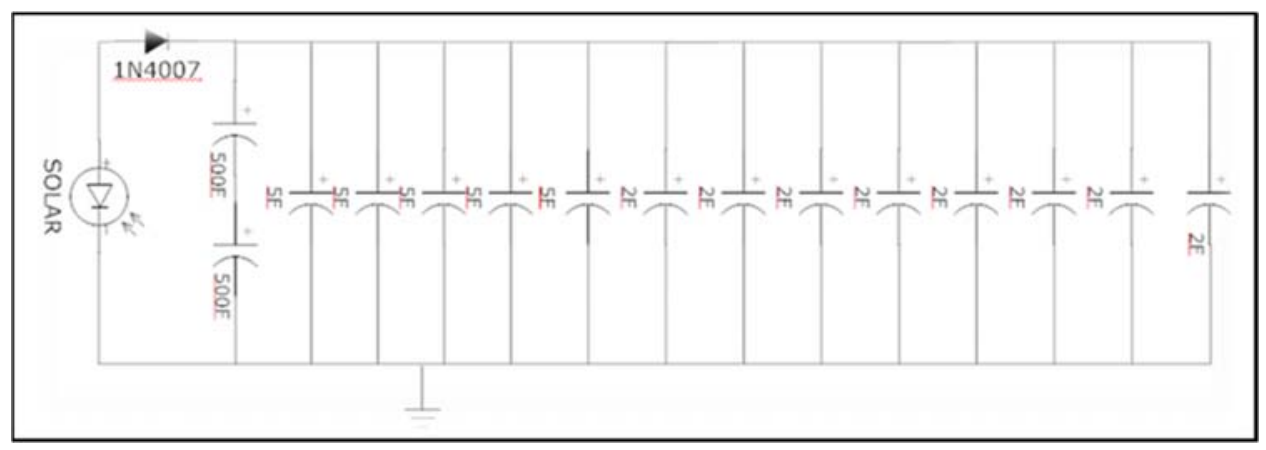

Figure 3 Circuit diagram of supercapacitors

Int J Pow Elec \& Dri Syst, Vol. 10, No. 1, March 2019 : $568-574$ 


\subsection{Charging time of supercapacitor using adapter}

results in Figure 4, the charging time of supercapacitor is fast rather than a battery. It just needed 20 minutes from $0.68 \mathrm{~V}$ to reach $5.05 \mathrm{~V}$. It shows that the charging time of supercapacitor in 20 minutes by using USB adapter $5 \mathrm{~V}$ and output current $2 \mathrm{~A}$. The voltage increases rapidly from 1 minute until 10 minutes. After that, the voltage rises slowly because the supercapacitor is truly suck up all the vitality it is given until full (with $>0.01$ Ohm ESR).

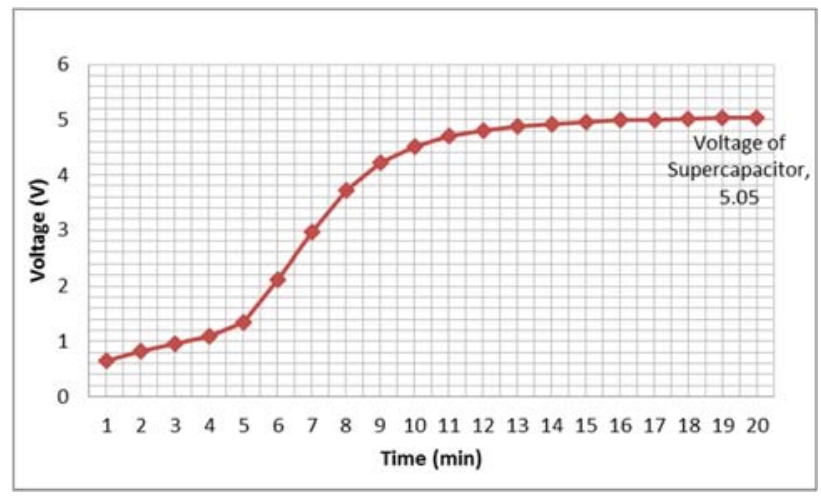

Figure 4. Charging Time of Supercapacitor using Adapter

\subsection{Charging time of supercapacitor using solar panel}

From sun irradiance, the solar panel produced the DC output voltage and could act as a backup power supply if there is no electricity or in the isolated area. However, the output of solar panels is depended on the intensity of light. The output voltage is increased as the intensity of light is increasing. Figure 5 shows that the output voltage can be reached until $7 \mathrm{~V}$ during peak hour.

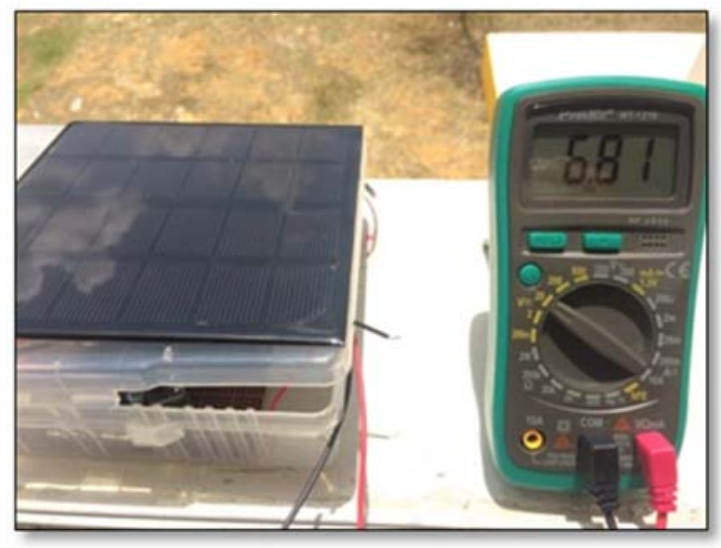

Figure 5. Output voltage of solar panel during peak hour

If $6.81 \mathrm{~V}$ (experimental value) is directly connected to the supercapacitor, it will damage the supercapacitor immediately. This is because the maximum charging voltage of supercapacitor is $5.4 \mathrm{~V}$. The protection way should be taken to avoid an unwanted explosion from the supercapacitor by using voltage regulator LM7805 to regulate the voltage to $5 \mathrm{~V}$. A diode $1 \mathrm{~N} 4002$ is used and connected in forwarding bias to the supercapacitor to avoid from reverse charging of solar panel.

Figure 6 shows that the voltage of supercapacitor is increasing gradually against time in 20 minutes. This is because the solar panel produced constant current to charge the supercapacitor. The specification of the solar panel is $6 \mathrm{~V}, 500 \mathrm{~mA}$. The weather condition on the day the experiment is conducted is a sunny day

A battery-less power supply using supercapacitor as energy storage ... (Mohammad Hadin A. Malek) 


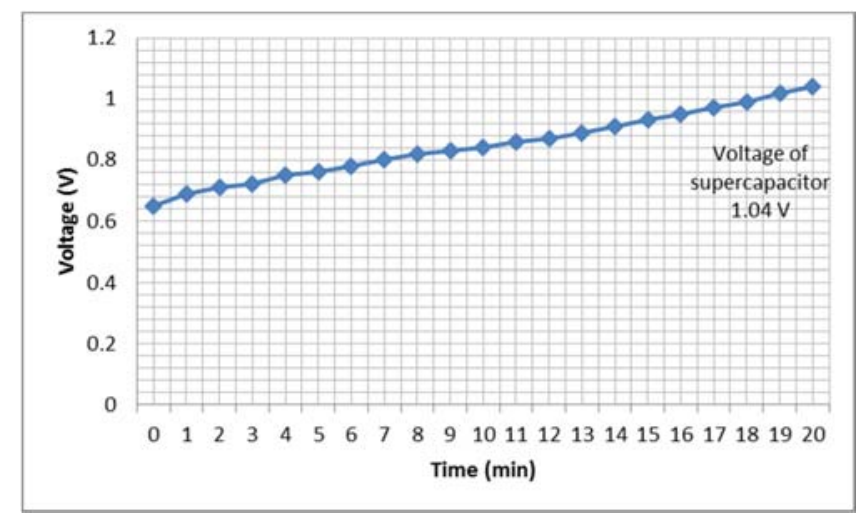

Figure 6. Charging time of supercapacitor using solar panel

\subsection{Charging Time of Supercapacitor using Solar Panel}

Figure 7 shows the higher the current, the shorter the time to charge the supercapacitor. The output current from the adapter is $2 \mathrm{~A}$ while the solar panel only produced $500 \mathrm{~mA}$ current. Then it will take a longer time when using solar panel compared to the adapter. This happens because the adapter gives constant power to the supercapacitor while the solar panel output power depends on the light intensity from the sun.

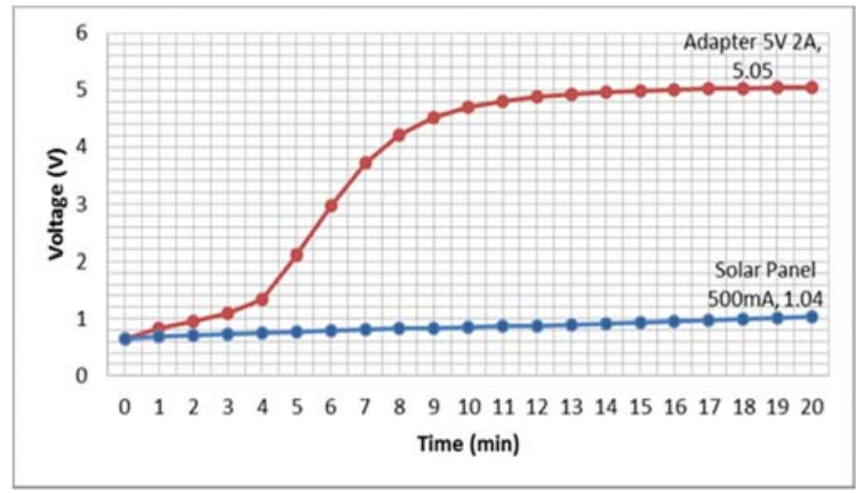

Figure 7. Comparison charging time between the adapter and solar panel

\subsection{Charging Time of Supercapacitor using Solar Panel}

Figure 8 shows the sine wave of the transmitter and receiver coil in different distances. In wireless power transfer, the distance between transmitter and receiver is the challenge for the efficiency of the product. This is because the difference of distance produces the different output voltage. Figure 8 (a) shows that the distance between the transmitter and receiver is $0 \mathrm{~cm}$, and the output voltage of the receiver is 21.6 V. Figure 8 (d) shows that the distance between the transmitter and receiver is $3 \mathrm{~cm}$, and the output voltage is $6 \mathrm{~V}$ When the distance between the transmitter and receiver increased, the output voltage at the receiver coil decreased due to the high frequency and low magnetic field produced. Higher efficiencies are only achieved at very short transmission distances between transmitter and receiver. It shows that for Figure 8 (a) the output voltage of the receiver is the highest value compared to other output voltage receiver. After the receiver coil receive the power, it rectified the AC to the DC using a bridge rectifier and filter using the capacitor. Even output voltage of the receiver coil does not reach $5 \mathrm{~V}$, the module of the receiver coil used boost converter and produced the output voltage $5 \mathrm{~V}$ to charge low power device. 


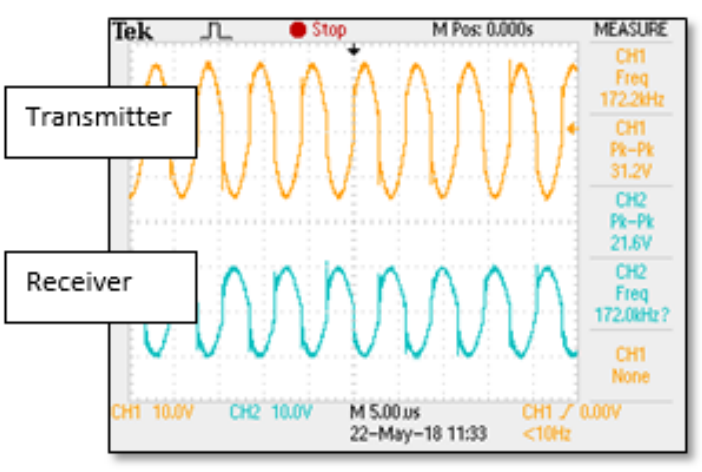

(a)

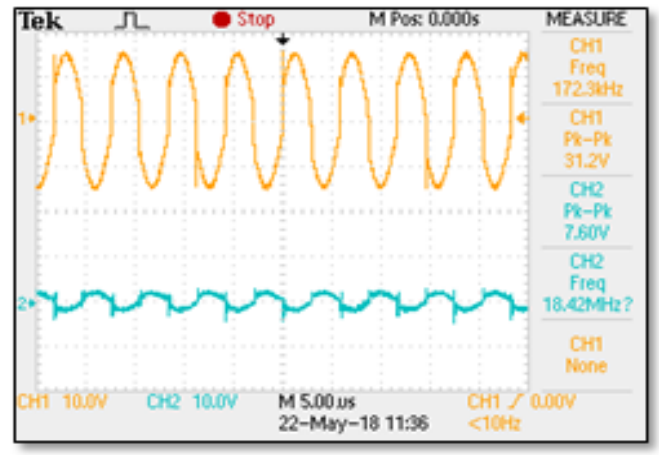

(c)

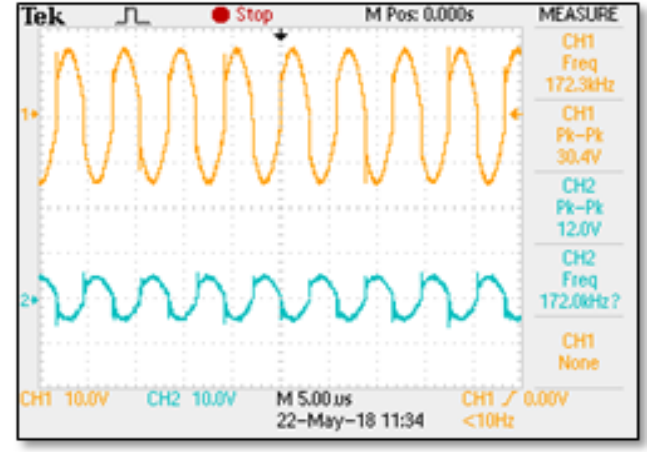

(b)

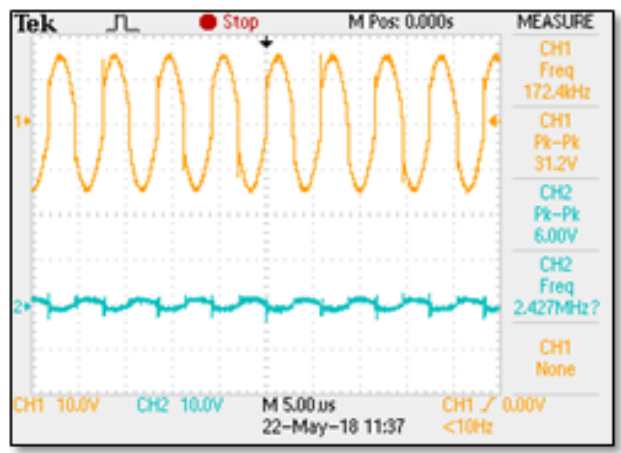

(d)

Figure 8. The Waveform of transmitter and receiver for (a) $0 \mathrm{~cm}$ (b) $1 \mathrm{~cm}$ (c) $2 \mathrm{~cm}$ and (d) $3 \mathrm{~cm}$

\subsection{Direct Power Supply}

The DC-DC boost converter is used to step up the voltage of supercapacitor and act as direct power supply unit in Figure 9. This project used a module of DC-DC boost converter using XL6009 as the main chip. The minimum input voltage to step up the voltage is between $3 \mathrm{~V}$ to $32 \mathrm{~V}$. The actual maximum output of DC-DC boost converter is $40 \mathrm{~V}$ but to avoid the module from damage, the tagging is used as a reference to the user. The voltage can be adjusted by using a potentiometer that is provided and the voltmeter will display the value change.

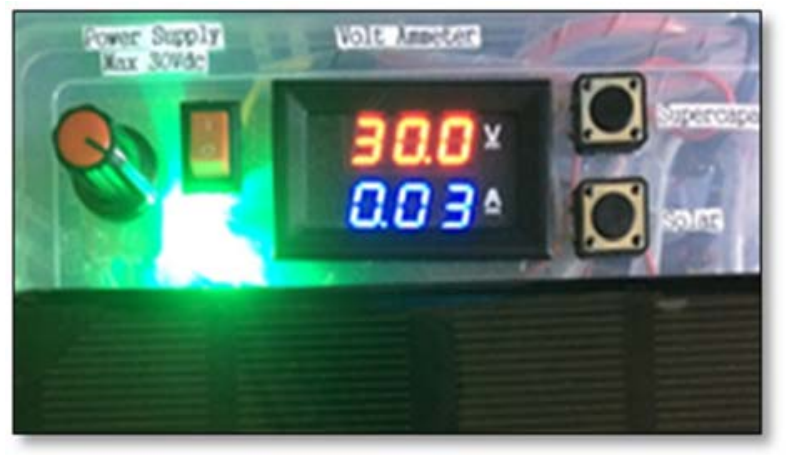

Figure 9. Power supply unit using DC-DC boost converter 


\section{CONCLUSION}

This paper presents a battery-less power supply using supercapacitor as energy storage powered by solar. In this study, a battery-less power supply using supercapacitor as energy storage is developed to charge low power device wirelessly or directly. This project is used WPT concept which transmits the electricity by overlapping of magnetic fields. The WPT concept is challenged since the efficiency of the WPT is depended on the distance between the transmitter and the receiver coil. Higher efficiency only achieved when the distance between the transmitter and the receiver is shorter. A direct power supply is provided to ease the users. This module is to provide the voltage output to $5 \mathrm{~V}$. The minimum input voltage step up is between 0.9 $\mathrm{V}$ to $4.8 \mathrm{~V}$. It also provides two USB socket with $0.6 \mathrm{~A}$ and $1.5 \mathrm{~A}$. Besides that, this study can be used as a power supply to the users when travelling as it can power up any electronic device such as a flashlight, DC motor, speaker and etc. The solar panel can be a backup supply if there is no electricity to charge supercapacitor.

For the future scope of this study, the supercapacitor can be hybrid energy by combining it with battery or renewable energy to ensure the supercapacitor can deliver the energy efficiently. Hybrid energy widely used since it has more advantage to the user and reduces energy consumption. The capacity of solar panel that used as a backup to charge the supercapacitor must be high output current so that it can charge the supercapacitor in a shorter time.

\section{ACKNOWLEDGEMENTS}

The authors gratefully acknowledge the support of the Malaysian Ministry of Higher Education (MOHE) through FRGS Research Grant No. 1615 and the Universiti Tun Hussein Onn Malaysia through Short-Term Grant No. U541.

\section{REFERENCES}

[1] L. Kouchachvili, et al., "Hybrid Battery/Supercapacitor Energy Storage System for the Electric Vechicles," Journal of Power Sources, vol. 374, pp 237-248, 2018.

[2] D.C. Rahn and C. Wang, "Battery System Engineering," The Pennyslvania State University, A John Wiley and Sons, Ltd. Publication, USA, 2013.

[3] Z. Cabrane, et al., "Analysis and Evaluation of Battery- Supercapacitor Hybrid Energy Storage System for Photovoltaic Installation," International Journal of Hydrogen Energy, vol.41, pp 20897-20907, 2016.

[4] M. A. Rosen, "Energy Storage," Nova Science Publisher, Inc., pp. 269-334, New York, 2012.

[5] N. Shinohara, "Wireless Power Transfer via Radio Waves," ISTE Lts \& John Wiley \& Sons Inc, Great Britain and USA, 2014.

[6] C.T. Rim, "Wireless charging of electrical vehicles," Power Electronic Handbook, vol 4, pp. 1113-1137, 2017.

[7] K.A. Kalwar, et al., "Inductively Coupled Power Transfer (ICPT) for electric vehicle charging," Renewable and Sustainable Energy Review, vol 47, pp. 462-475, March 2015.

[8] S. S. Mohammed, et al., "Wireless Power Transmission: A Next Generation Power Transmission System," International Journal of Computer Applications, vol. 1, pp. 0975-8887, 2010.

[9] M. Fareq, et al., "Solar Wireless Power Transfer Using Inductive Coupling for Mobile Phone Charger," IEEE 8th International Power Engineering and Optimization Conference (PEOCO2014), vol.8, pp. 473-476, March 2014.

[10] N. Shinohara, "Wireless Power Transfer via Radio waves," Great Britain \& USA: ISTE Ltd \& John Wiley \& Sons, Inc., 2014.

[11] A. Nasirudin and R.Chao, "Solar Powered Boat Design Optimization," Procedia Engineering, vol. 194, pp 260-267, 2017.

[12] P.Breeze, "An Introduction to Solar Power: Solar Power Generation," Elseiver Ltd., pp 1-8, 2016. 